\title{
Contribuição à hidroquímica de drenagens no Município de Manaus - AM
}

\author{
Adriana Maria Coimbra HORBE ${ }^{1}$ Israel Leibnitz Ferreira GOMES ${ }^{1}$; Sebastião Fonseca MIRANDA ${ }^{2}$; Maria do \\ Socorro Rocha da SILVA ${ }^{2}$
}

\begin{abstract}
RESUMO
O rio Puraquequara, e seu afluente direito, o igarapé Água Branca, localizam-se fora da zona urbana de Manaus e estão com a bacia ainda protegida por floresta primária. Têm características geológicas, pedológicas e climatológicas de igarapés naturais de terrafirme da Amazônia Central. Foram coletadas amostras de água nos meses de novembro de 1998 (período seco) e abril de 1999 (período chuvoso) e determinados os parâmetros temperatura, $\mathrm{pH}$, turbidez, condutividade, alcalinidade, dureza, $\mathrm{DQO}, \mathrm{Ca}^{2+}$, $\mathrm{Mg}^{2+}, \mathrm{Na}^{+}, \mathrm{K}^{+}, \mathrm{SiO}_{2}, \mathrm{NO}_{3}^{-}, \mathrm{NO}_{2}^{-}, \mathrm{PO}_{4}^{3-}, \mathrm{SO}_{4}^{2-}, \mathrm{Cl}^{-}, \mathrm{NH}_{4}^{+} \mathrm{e}$ Fe total. As águas apresentaram $\mathrm{pH}$ entre 3,8 e 4,1 passando a menos ácidas na estiagem. A alcalinidade e a turbidez são, em geral, mais elevadas na estiagem, enquanto a condutividade, dureza e DQO são maiores no período mais chuvoso. $\mathrm{SiO}_{2} \mathrm{e} \mathrm{o} \mathrm{Cl}$ foram os ânions mais abundantes, com contribuição maior do primeiro no Puraquequara e menor no Água Branca, enquanto o $\mathrm{Cl}^{-}$tem comportamento oposto. $\mathrm{Na}^{+}$, Fe total $\mathrm{NH}_{4}^{+}$são os cátions mais abundantes e predominam, no geral, no período mais seco. $\mathrm{O} \mathrm{NH}_{4}^{+}$é o único cátion que tende a aumentar sua contribuição para jusante do igarapé no período úmido. Os teores de $\mathrm{K}^{+}$são mais elevados do que os de $\mathrm{Mg}^{2+}$ e este que os de $\mathrm{Ca}^{2+}$, e são todos

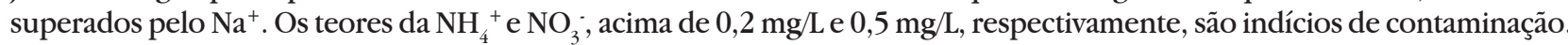
Essas características definem as águas da bacia como muito diluídas, com predominância dos ânions sobre os cátions e correlacionáveis as águas de cor preta.
\end{abstract}

\section{PALAVRAS CHAVE}

Águas naturais, rios da Amazônia, águas pretas, parâmetros físicos.

\section{Contribution to the bydrochemistry of drainages in the municipality of Manaus-Am}

\begin{abstract}
The Puraquequara River and its right-bank's tributary, the Água Branca stream, are located in the outskirts of the Manaus urbanized area and their basin is still harbored by the primary rain forest cover. They exhibit 'terra firme' geologic, pedologic and climatological characteristics pertaining to the Amazonian region. Samples for this research were collected in November 1998 (dry season) and April 1999 (rainy season). Water temperature, pH, turbidity, conductivity, alkalinity, hardness, COD, $\mathrm{Ca}^{2+}, \mathrm{Mg}^{2+}, \mathrm{Na}^{+} \mathrm{e} \mathrm{K}^{+}, \mathrm{SiO}_{2}, \mathrm{NO}_{3} ; \mathrm{NO}_{2} ; \mathrm{PO}_{4}^{3-}, \mathrm{SO}_{4}^{2-}, \mathrm{Cl}_{2} \mathrm{NH}_{4}^{+}$and Fe were analysed. The water is acid (3.8 to 4.1) turning into less acid in the dry season. The alkalinity and turbidity are higher in the dry season whereas conductivity, hardness and COD are bigher in the rainy season. $\mathrm{SiO}_{2}$ and $\mathrm{Cl}$ are the main anionic elements where the former's contribution is higher in the Puraquequara and lower in the Água Branca while the latter shows inverse contribution. $\mathrm{Na}^{+}, \mathrm{Fe}$, and $\mathrm{NH}_{4}^{+}$are the main cations with their higher contribution in the dry season. $\mathrm{NH}_{4}^{+}$is the only cation that tends to increase its contribution downstream in the wet season. $\mathrm{K}^{+}$contents is higher than that of $\mathrm{Mg}^{+}$and $\mathrm{Ca}^{2+}$ yet $\mathrm{Na}^{+}$is the highest. The higher than $0.2 \mathrm{mg} / \mathrm{L}$ and $0.5 \mathrm{mg} / \mathrm{L}$ amounts of $\mathrm{NH}_{4}^{+}$and $\mathrm{NO}_{3}^{-}$respectively, are traces of water contamination. These characteristics define these waters as very diluted with anions predominating over cations and correlated to the black water of the region.
\end{abstract}

\section{KEYWORDS}

Natural waters, Amazonian river, black water, physical and chemical parameters.

\footnotetext{
${ }^{1}$ Departamento de Geociências - Universidade Federal do Amazonas, Av. Gal. Rodrigo O. J. Ramos 3000, Japiim, 69077-000, Manaus -AM, ahorbe@ ufam.edu.br. 2 . Coordenação de Pesquisa em Clima e Recursos Hídricos, Instituto de Pesquisas da Amazônia, Alameda Cosme Ferreira 1756, Cx Postal 478, 69083-000, Manaus, AM.
} 


\section{ACTA \\ AMAZONICA}

CONTRIBUIÇÃO À HIDROQUIIMICA DE

DRENAGENS NO MUNICÍPIO DE MANAUS - AM

\section{INTRODUÇÃO}

O município de Manaus está sob forte impacto ambiental causado pela ocupação urbana desordenada em conseqüência da falta de políticas públicas de gestão territorial. Atualmente, os igarapés que drenam a cidade estão totalmente degradados pelo aporte de efluentes domésticos e industriais (Silva, 1996; Barroncas, 1999; Silva et al, 1999, entre outros). Com o avanço da urbanização novas áreas estão em fase de degradação sem que se conheçam as características originais das suas águas superficiais, que são os melhores parâmetros para medir a qualidade, o grau de impacto, entender os mecanismos que controlam a concentração dos elementos químicos nos rios (Shiller, 1997), caracterizar a lixiviação e a ciclagem das espécies químicas (Forti et al., 1997) e estimar processos erosivos (Dupré et al. 1996) e de transporte dos elementos nas águas naturais (Viers et al., 1997). Todas essas informações permitem otimizar o gerenciamento dos recursos hídricos de uma região. Assim, os dados obtidos, somados aos de Silva et al. (1999), Campos (1994) e aos preliminares de Lopes \& Silva (1999) e Lima \& Miranda (2000), em outras drenagens do município de Manaus, contribuirão para montar um quadro sobre a composição média das águas não contaminadas na região. Essas informações também servirão para quantificar o grau de contaminação dos igarapés na área urbana da cidade de Manaus, contribuindo para entender a cinética dos processos de poluição no decorrer dos anos nas drenagens mais impactadas.

\section{Localização e características da área}

O rio Puraquequara e seu maior afluente direito, o Água Branca, estão localizados na zona rural leste do município de Manaus, na área de expansão da cidade, e lançam suas águas no rio Amazonas (Fig. 1). A foz do Puraquequara é afogada em conseqüência do barramento de sua água pela deposição de sedimentos trazidos pelo Amazonas, de modo que se forma um lago tipo ria com até $1 \mathrm{~km}$ de largura na sua foz. A influência do barramento se estende até $7 \mathrm{~km}$ a montante. A rodovia AM010 , que passa próximo às cabeceiras, e estradas vicinais permitiram o acesso aos pontos de amostragem.

O substrato geológico da bacia do Puraquequara é composto pelos sedimentos da Formação Alter do Chão, constituída de arenitos arcoseanos, quartzo-arenitos, quartzo-grauvacas e brechas intraformacionais, depositadas em ambiente flúviolacustre entre o Cretáceo Superior e o Terciário Inferior (Cunha et al., 1994). Essas rochas estão lateritizadas e formam extensos perfis imaturos, geralmente truncados. Os horizontes desses perfis são constituídos basicamente por caulinita, quartzo, goethita, hematita e, às vezes, gibbsita, recobertos por solos amarelados do tipo Latossolos e Spodossolos.

A cobertura vegetal da regiãoé de floresta tropical quase que totalmente preservada, contudo, há moradores na área, especialmente em sítios na sua cabeceira, e balneários ao longo dos cursos das drenagens. O clima da região é tropical quente (média de $26^{\circ} \mathrm{C}$ ) e chuvoso (média de $2100 \mathrm{~mm} / \mathrm{ano}$ ), com o período das chuvas se estendendo de dezembro a junho e é mais no restante do ano.

\section{MATERIAL E MÉTODOS}

Foram coletadas cinco amostras de água ao longo do rio Puraquequara e seis em seu afluente o igarapé Água Branca em novembro de 1998, correspondente ao período mais seco. Em abril de 1999, período chuvoso, foram amostrados somente os seis pontos do Água Branca, devido a dificuldade de acesso ao Puraquequara, por estarem as suas margens muito alagadas.

As amostras foram acondicionadas em garrafas de polietileno previamente limpas com $\mathrm{HCl} 10 \%$ e água deionizada. Após a coleta, as amostras foram filtradas com membrana millipore de $1,2 \mathrm{~mm}$. Foram determinados os parâmetros temperatura, $\mathrm{pH}$ e condutividade por potenciometria e turbidez por turbidimetria. As análises de alcalinidade, dureza, demanda química de oxigênio (DQO), $\mathrm{Ca}^{2+}, \mathrm{Mg}^{2+}$ foram realizadas por titulometria, $\mathrm{Na}^{+}$e $\mathrm{K}^{+}$por fotometria de chama, $\mathrm{SiO}_{2}, \mathrm{NO}_{3}$, $\mathrm{NO}_{2} ; \mathrm{PO}_{4}^{3-}, \mathrm{SO}_{4}^{2-}, \mathrm{Cl}, \mathrm{NH}_{4}^{+} \mathrm{e} \mathrm{Fe}$ total por espectrofotometria ótica pelo do método FIA no Laboratório de Limnologia do Instituto Nacional de Pesquisa da Amazônia atendendo as especificações do Standard Method.

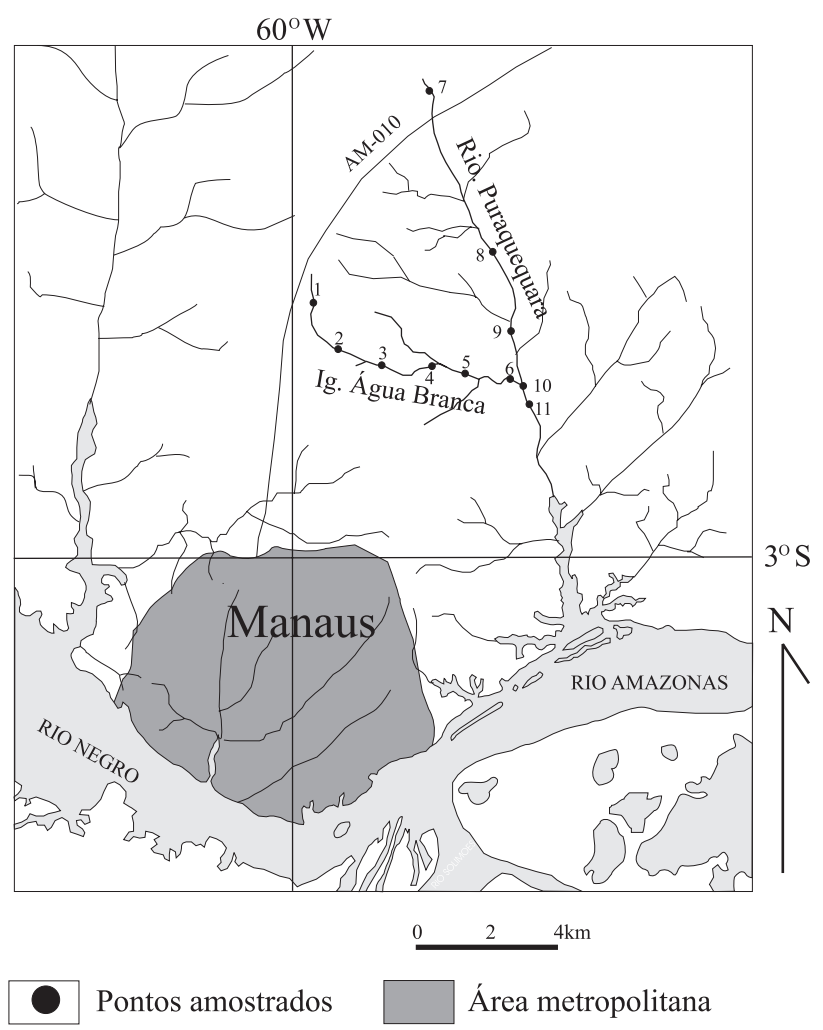

Figura 1 - Localização da bacia do Puraquequara e dos pontos de coleta. 


\section{ACTA \\ AMAZONICA}

\section{RESULTADOS E DISCUSSÃO}

\section{Características físico-químicas}

A temperatura da água, medida somente no igarapé Água Branca, teve pequena variação ao longo do igarapé nos dois períodos analisados, entre $26^{\circ} \mathrm{C} \mathrm{e} 27^{\circ} \mathrm{C}$ no chuvoso, em abril de 1998 , e de $24,9^{\circ} \mathrm{C}$ a $26^{\circ} \mathrm{C}$ no seco, em novembro de 1998 (Tab. 1). O índice pluviométrico na região nesses meses foi de $377,3 \mathrm{~mm}$ e de $234,4 \mathrm{~mm}$, respectivamente.

No período chuvoso o pH variou entre 3,8 e 4,1 no igarapé Água Branca, tornando-se mais alcalino no seco entre 4,8 e 5,4 e com valores similares no Puraquequara (Tab. 1). Esses valores são típicos de rios de águas pretas (Sioli 1957, Santos et al 1985, Santos e Ribeiro 1988, Konhauser et al 1994, Dupré et al 1996, Gaillardet et al 1997 e Küchler et al., 2000) e compatíveis com outros igarapés próximos (Campos, 1994; Silva et al., 1999) e com as águas de precipitação na região (Neiva \& Cunha, 2000). A menor acidez no período seco difere do observado por Silva et al. (1999) no igarapé Barro Branco, também localizado nas proximidades da área urbana de Manaus. Para estes autores, a maior acidez está relacionada ao aumento da concentração de cátions no período chuvoso, fato que, aparentemente, não se aplica a bacia do Puraquequara. Contudo, para Walker (1995) as variações no pH independem do regime pluviométrico.

As características físico-químicas indicam pouca turbidez e valores baixos de condutividade, alcalinidade, dureza e DQO (Tab. 1), aspectos típicos de águas límpidas e pobres em material dissolvido. Há variações desses parâmetros entre o período chuvoso e seco no igarapé Água Branca, de modo que a condutividade, dureza e DQO são maiores no primeiro período e a turbidez e a alcalinidade são no segundo período. Ao longo da drenagem, o que mais varia é a turbidez, especialmente no período seco, e alcança 41 FTU no ponto 1. O Puraquequara apresenta, em média, menor turbidez e maior condutividade, enquanto os demais parâmetros tem variação dentro dos limites do Água Branca. Os valores de condutividade são compatíveis com os determinados nas águas do rio Negro por Kuchler et al. (2000).

A maior alcalinidade na estiagem afeta diretamente o $\mathrm{pH}$ da água, enquanto no período mais úmido o $\mathrm{pH}$, inferior a 4,3, indica ausência das formas carbonatos e bicarbonatos livres. A dureza, menor que $0,62 \mathrm{mg} / \mathrm{L}$ (Tab. 1 ), que reflete a quantidade de cálcio e magnésio, permite classificar as águas como moles (menos que 3,35 mg/L de $\mathrm{CaCO}_{3}$ ).

\section{Parâmetros químicos}

$\mathrm{OSiO}_{2}$ é o ânion mais abundante, seguido do $\mathrm{Cl}$ ( $\mathrm{Tab} 1 \mathrm{e} \mathrm{Fig.}$ 2). Ambos representam pelo menos $98 \%$ da carga de ânions das águas do igarapéÁgua Branca e 88\% da do Puraquequara, quando comparados com o $\mathrm{NO}_{3}$ : $\mathrm{O} \mathrm{PO}_{4}^{3}, \mathrm{NO}_{2} \cdot \mathrm{e} \mathrm{SO}_{4}^{2-}$ estão abaixo ou próximo do limite de detecção $(0,001,0,005$ e $0,005 \mathrm{mg} / \mathrm{L}$ respectivamente). Não há variação significativa entre os períodos seco e o chuvoso e a contribuição do $\mathrm{Cl}$ no Puraquequara tende a ser um pouco menor que no Água Branca (Fig. 2).

Os teores de $\mathrm{SiO}_{2}$ e $\mathrm{Cl}^{-}$são compatíveis com os encontrados por Campos (1994), Santos et al. (1985), Furch (1984), entre outros na Amazônia. As fontes de cloro nas águas não contaminadas são os aerossóis marinhos dissolvidos na água da chuva e as rochas evaporíticas (Gaillardet et al., 1997). Desse modo, na ausência desse tipo de rocha, os teores 0,7 $\mathrm{mg} / \mathrm{L}$ e $1,2 \mathrm{mg} / \mathrm{L}$ de cloreto podem ser atribuídos a aportes pela água da chuva, enquanto que o $\mathrm{SiO}_{2}$, com teor um pouco maior nas águas do Puraquequara (Tab. 1), é resultante, provavelmente, unicamente do intemperismo das rochas da Formação Alter do Chão.

$\mathrm{O} \mathrm{NO}_{3}^{-}$influencia em menos de $5 \%$ a composição das águas estudadas, exceto no ponto 8 do Puraquequara, onde alcança $12 \%$ (Fig. 2). Apresenta, em média, maior concentração no período chuvoso no igarapé Água Branca, com destaque para o ponto $1(0,16 \mathrm{mg} / \mathrm{L})$, decrescendo para jusante (Tab. 1$)$.

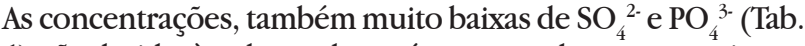
1), são devidas à pobreza desses íons nas rochas que constituem a Formação Alter do Chão e a baixa mobilidade de seus compostos, especialmente o fosfato, que tende a se combinar com o alumínio precipitando. As concentrações desses quatro ânions são compatíveis com os de águas consideradas não impactadas na região (Silva et al, 1999 e Campos, 1994), exceto no ponto 8 do Puraquequara, cujo teor de $0,51 \mathrm{ml} / \mathrm{L} \mathrm{de} \mathrm{NO}_{3}$ está no limite do aceitável pelo CONAMA 20.

Sódio, nitrogênio amoniacal e ferro total contribuem com 67\% a 100\% da carga catiônica das águas estudadas e são, em relação aos demais $\left(\mathrm{Ca}^{2+}, \mathrm{Mg}^{2+} \mathrm{eK}^{+}\right)$, os cátions mais abundantes nas águas estudados (Fig. 2). $\mathrm{O} \mathrm{NH}_{4}^{+}$é o único cátion que aumenta sua contribuição para jusante do Puraquequara, no período seco, enquanto no Água Branca o acréscimo se dá no período chuvoso. $\mathrm{O} \mathrm{Na}^{+}$aumenta somente no período seco (Fig. 2). Comparativamente, os teores de $\mathrm{NH}_{4}^{+}$são mais elevados no período chuvoso nos pontos $2,4,5$ e 6 , enquanto nos demais predominam no seco, atingindo a maior concentração no ponto $3(1,1 \mathrm{mg} / \mathrm{L})$ do igarapé Água Branca (Tab. 1). O Fe total varia de contribuição entre os dois períodos considerados e ao longo das drenagens (Tab. 1 e Fig. 2).

Dentre os compostos nitrogenados, $\mathrm{O} \mathrm{NH}_{4}^{+}$é o que apresenta concentração mais alta (Tab. 1), provavelmente por ser produto de excreção direta dos seres vivos, mas descargas elétricas que promovem a reação do nitrogênio com o oxigênio na atmosfera também podem contribuir no teor desse cátion, especialmente em águas naturais. A oxidação de $\mathrm{NH}_{4}^{+}$libera $\mathrm{NO}_{2}{ }^{-} \mathrm{e}$, posteriormente $\mathrm{NO}_{3} \cdot \mathrm{o}$ que justifica os baixos teores do nitrito por ser a fase intermediária, todos eles são bons indicadores de degradação do ambiente. Os teores de $\mathrm{NH}_{4}^{+}$, acima de 0,2 mg/L no igarapé Água Branca, são indícios de ação antrópica, que se acentua no ponto 3 no período mais seco $(1,10 \mathrm{mg} / \mathrm{L})$, mas diminui para $0,15 \mathrm{mg} / \mathrm{L}$ na confluência com o Puraquequara (Tab. 1)..

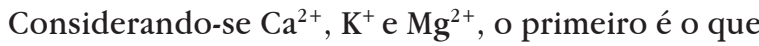
tem menor contribuição, especialmente no período seco $(<1 \%)$ e o $\mathrm{K}^{+}$a maior, com tendência a aumentar para o 


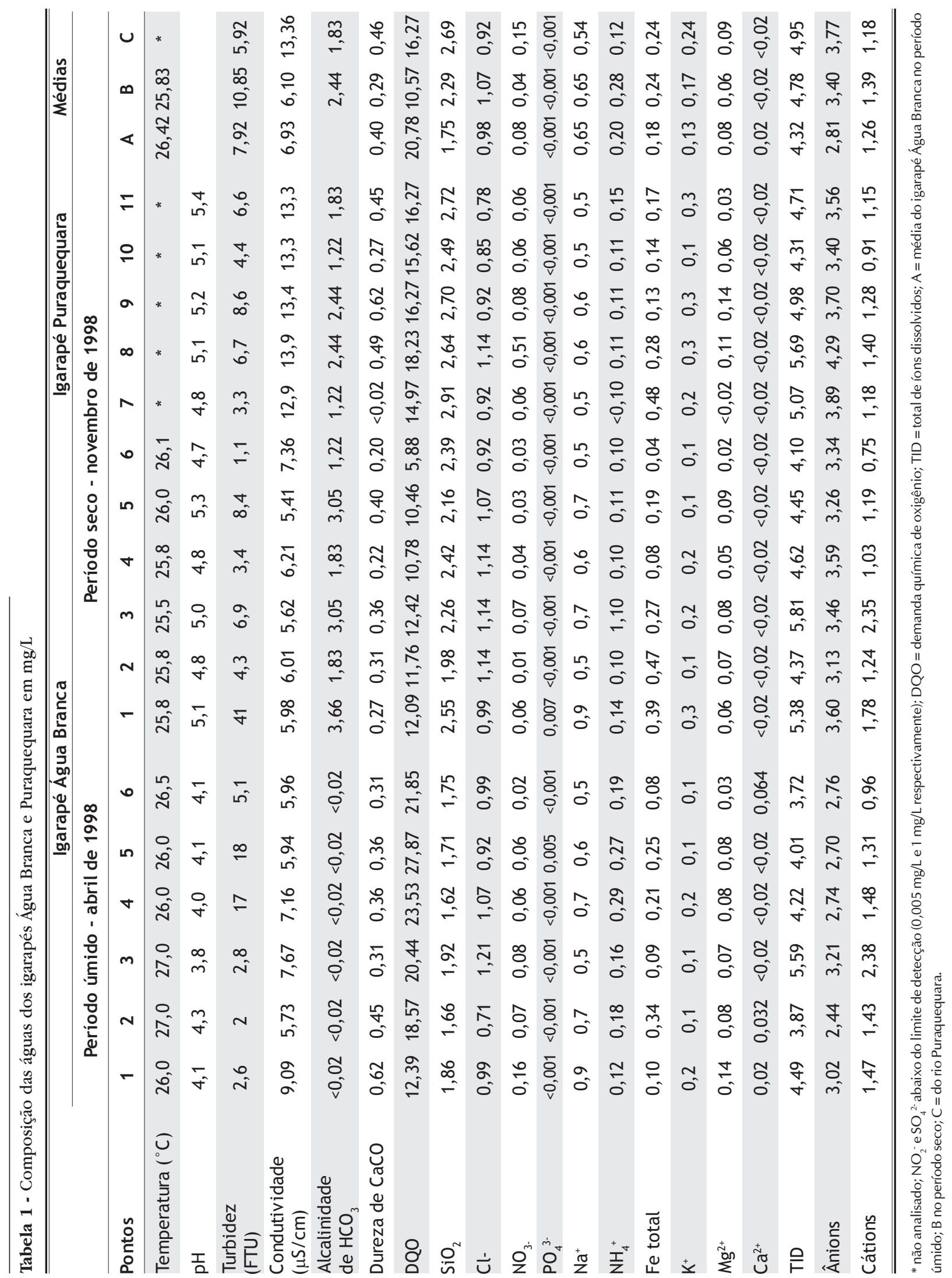




\section{ACTA \\ AMAZONICA}

CONTRIBUIÇÃO À HIDROQUÍMICA DE

DRENAGENS NO MUNICÍPIO DE MANAUS - AM período seco e para o Puraquequara (Tab. 1 e Fig. 2) onde alcançam 33\%. Estes cátions, juntamente com os altos teores de $\mathrm{SiO}_{2}$, sugerem a forte contribuição dos minerais silicáticos que constituem as rochas da Formação Alter do Chão e dos Espodossolos e Latossolos gerados a partir do seu intemperismo (Horbe et al 2004). Contudo, Neiva \& Cunha (2000) constataram teores de até $0,9 \mathrm{mg} / \mathrm{L}$ de $\mathrm{Na}^{+}$nas águas de precipitação na região de Manaus o que sugere que esta pode ser a principal fonte desse elemento e justificaria seus teores mais elevados em relação aos demais cátions. Outro fator que contribui para a concentração mais elevada de $\mathrm{Na}^{+}$ nas águas é sua alta solubilidade e mobilidade por não entrar na formação da maioria dos minerais intempéricos. Pode haver uma pequena contribuição antrópica desses elementos, mas ainda imperceptível. Os teores de $\mathrm{SiO}_{2}$, $\mathrm{Na}^{+}, \mathrm{K}^{+}, \mathrm{Mg}^{2+}$ e Ca ${ }^{2+}$ cujas concentrações são decrescentes entre si, são correlacionáveis aos obtidos por Konhauser et al. (1994) nas águas do rio Negro.

O total de íons dissolvidos (TID) varia no período de estiagem entre $4,1 \mathrm{mg} / \mathrm{L} \mathrm{e} 5,8 \mathrm{mg} / \mathrm{L}$ nos pontos analisados $\mathrm{e}$ não há diferenças marcantes entre o Água Branca e o Puraquequara no período seco (Tab. 1). No período úmido a concentração do material dissolvido nas águas do Água Branca é ainda menor, entre 3,7 mg/L e 5,6 mg/L indicando que estas são um pouco mais diluídas.

Na carga total dissolvida há predominância dos ânions sobre os cátions (Tab. 1), especialmente no Puraquequara no período de estiagem, cuja razão entre eles alcança 3,2 $\mathrm{mg} / \mathrm{L}$. Essa diferença na carga química, que pode ser atribuída à falta de quantificação de outros íons, é natural nos rios de água clara e preta na Amazônia (Campos 1994, Dupré et al. 1996, Silva et al 1999 e Küchler et al., 2000). Essa deficiência em íons também pode explicar a não correlação entre a carga total dissolvida e a condutividade, apesar de que, segundo Küchler et al. (2000), em rios de água preta o carbono orgânico é que mantém correlação com esse parâmetro. Observa-se, também, uma relação direta entre a carga total dissolvida, um pouco maior na estação seca, em conseqüência da menor diluição das águas pela chuva, e o pH mais elevado, o que sugere relação de dependência.

\section{CONCLUSÃO}

Os parâmetros analisados e a composição química mostram que as águas dos igarapés Água Branca e Puraquequara são altamente diluídas com predominância dos ânions sobre os cátions. $\mathrm{SiO}_{2} \mathrm{e} \mathrm{Cl}$ são os ânions mais abundantes, destacando-se $\mathrm{o} \mathrm{Na}^{+}$dentre os cátions. $\mathrm{SiO}_{2}$, $\mathrm{Ca}^{2+}, \mathrm{Mg}^{2+}, \mathrm{K}^{+}$e Fe total são, provavelmente, provenientes unicamente do intemperismo das rochas sedimentares da Formação Alter do Chão, enquanto o $\mathrm{Na}^{+}$pode ter essa mesma proveniência e também a partir de águas pluviais. Os teores de $\mathrm{Cl}^{-}$apesar do estarem acima do esperado para as rochas da Formação Alter do Chão, são compatíveis com a composição química das águas da região. Apesar da falta da quantificação dos íons orgânicos, é possível, com base no $\mathrm{pH}$ e nos teores de $\mathrm{Na}^{+}$e $\mathrm{SiO}_{2}$, correlacionar essas águas com as de cor preta.

Dentre os compostos nitrogenados destacam-se $\mathrm{NH}_{4}^{+} \mathrm{e}$ $\mathrm{NO}_{3}$, cujos teores acima de $0,2 \mathrm{mg} / \mathrm{L}$ e $0,5 \mathrm{mg} / \mathrm{L}$, respectivamente, são indícios de contaminação. $\mathrm{O} \mathrm{NH}_{4}^{+}$é o único cátion que tende a aumentar de concentração para jusante no período chuvoso. $\mathrm{SO}_{4}^{2-}, \mathrm{PO}_{4}^{3-}$ e $\mathrm{NO}_{2}^{-}$têm concentrações próximas ou abaixo do limite de detecção.

A alcalinidade, condutividade e dureza retratam a baixa concentração iônica das águas típicas de áreas tropicais. A alcalinidade e a turbidez são, em geral, mais elevadas no período seco, enquanto a condutividade, dureza e DQO são maiores no chuvoso.

Observa-se, portanto, a influência tanto do intemperismo das rochas sedimentares da Formação Alter do Chão, responsável pela geração de Espodossolos e Latossolos na região, bem como da ação da chuva e do homem na composição química das águas do Puraquequara e Água Branca, em conseqüência da interação desses fatores no ciclo hidrológico.

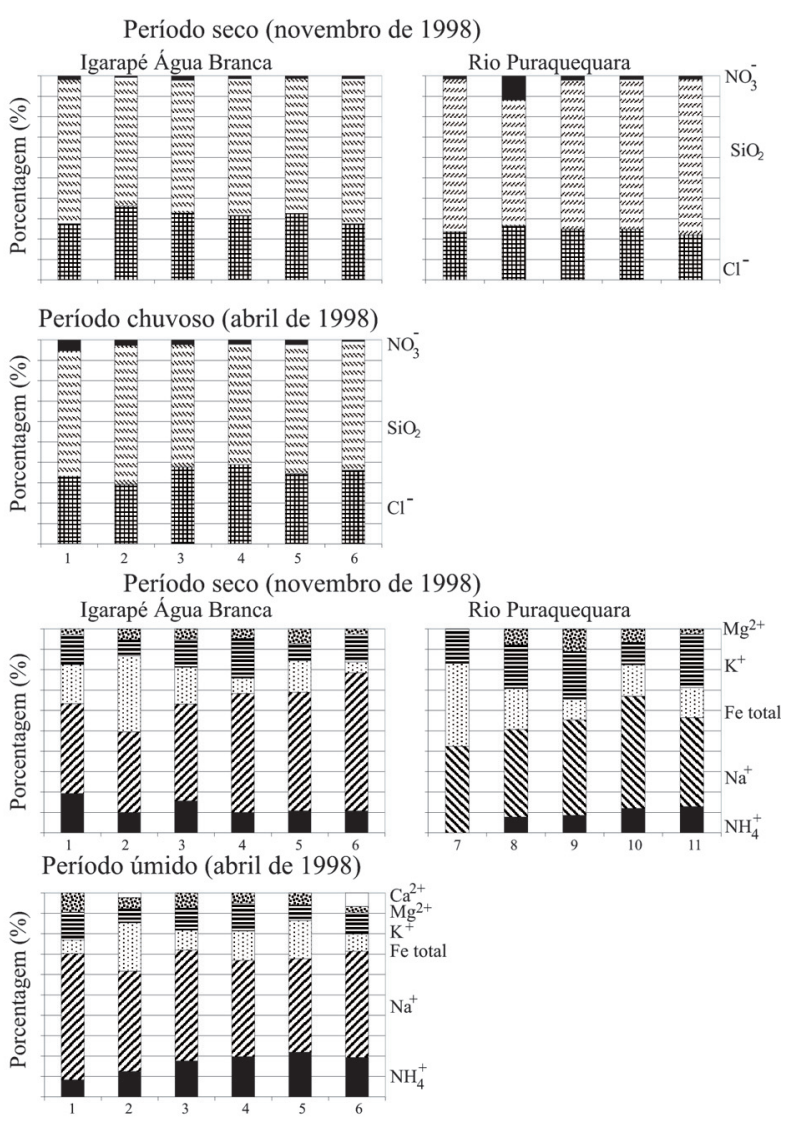

Figura 2 - Proporção dos íons na composição química das águas do rio Puraquequara e no igarapé Água Branca. Pontos 1 a 11 correspondem aos locais amostrados. 


\section{AGRADECIMENTOS}

A Universidade Federal do Amazonas e ao Instituto Nacional de Pesquisa da Amazônia, pela bolsa de iniciação científica (PIBIC/UFAM) do segundo autor e pela infraestrutura dos laboratórios.

\section{BIBLIOGRAFIA CITADA}

Barroncas, P.P. 1999. Estudo da Concentração de Metais nos Igarapés Acará, Matrinchã. Dissertação (Mestrado em Ciências do Meio Ambiente). Programa Centro de Ciências do Ambiente, Universidade Federal do Amazonas. Manaus. 105p.

Campos, Z.E.S. de 1994. Parâmetros físico-químicos em igarapé de água clara e preta ao longo da rodovia BR-174 entre Manaus e Presidente Figueiredo - AM. INPA; Dissertação de Mestrado, pós-graduação em Biologia Tropical e Recursos Naturais. 90p.

Cunha, P.R.C.; Gonzaga, F.G.; Coutinho,L.F.C.; Feijó, F.J. 1994. Bacia do Amazonas. Boletim de Geociências da PETROBRAS, 8:47-55.

Dupré, B.; Gaillardet, J.; Rousseau, D.; Allégre, J. 1996. Major and trace elements of river-borned material: The Congo Basin. Geochimica et Cosmochimica Acta, 60:1301-1321.

Forti, M.C.; Melfi, A.J.; Amorim, P.R.N. 1997. Hidroquímica das águas de drenagem de uma pequena bacia hidrográfica no nordeste da Amazônia (Estado do Amapá, Brasil): efeitos da sazonalidade. Geochimica Brasiliensis, 11:325-340.

Furch, K, 1984. Water chemistry of the Amazon Basin: the distribution of chemical elements among freshwaters. In: Sioli, H. (ed.). The Amazon - Limnology and landscape ecologyof a mighty tropical river and its basin. Junk, Dordrecht: p.167-169.

Gaillardet, J.; Dupré, B.; Allégre, J.; Négrel, P. 1997. Chemical and physical denudation in the Amazon river basin. Chemical Geology, 142:141-173.

Horbe, A.M.C.; Horbe, M.A.; Suguio, K. Contribution to the study of tropical spodosolos in northeastern Amazonas State, Brazil. Geoderma, 119:55-68

Konhauser, K.O.; Fyfe, W.S.; Kronberg, B.I. 1994. Multi-element chemistry of some Amazonian waters and soils. Chemical Geology, 111:155-175.
Kulcher, I.L.; Miekeley, N.; Forsberg, R. 2000. A contribution to the chemical characterization of rivers in the rio Negro basin, Brazil. J. Braz. Chem. Soc., 11:286-292.

Lima, R.M.S.; Miranda, S.A.F. 2000. Estudo físico-químico dos tributários da margem esquerda do rio Puraquequara.Jornada de Iniciação Científica do INPA, 9ª , Manaus. p.191-193

Lopes, A.P.; Silva, M.S.R 1999. Hidroquímica das águas de superfícies da bacia do Puraquequara - Manaus-AM.Jornada de Iniciação Científica do INPA, ${ }^{\mathrm{a}}$, Manaus. p.191-193

Neiva, M.; Cunha, H.B. 2000. Estudo da composição química das precipitações sobre a região de Manaus. Jornada de Iniciação Científica do INPA, 9a, Manaus. p.340-343.

Santos, U.M.; Bringel, S.R.B.; Ribeiro, M.N.G.; Silva, M.N.P. 1985. Rios da Bacia Amazônica. II. Os afluentes do rio Branco. Acta Amazonica, 15:147-156.

Santos, U. M. e Ribeiro, M. N. G. 1988. A Hidroquímica do rio Solimões-AM. Acta Amazonica, 18 (3-4): 145-172.

Shiller, A.M. 1997. Dissolved trace elements in the Mississipi River: Seasonal, interannual, and decadal variability. Geochimica et Cosmochimica Acta, 61:4321-4330.

Silva, M.S.R. 1996. Metais pesados em sedimentos de fundo de igarapés (Manaus-AM). Dissertação de Mestrado, CPGGUFPa, 107p.

Silva, M.S.R.; Ramos, J.P.; Pinto, A.G..N. 1999. Metais de transição nos sedimentos de igarapés de Manaus-AM. Acta Limnologica Brasiliensis, 11:89-100.

Sioli, H. 1957. Valores de pH de águas Amazônicas. Boletim do Museu Paraense Emilio Goeldi. Geologia, 1, 1-35.

Viers, J.; Dupré, B.; Polvé, M.; Schott, J.; Dandurand, J-L.; Braun, J-J. 1997. Chemical weathering in the drainage basin of the tropical watershed (Nsimi-Zoetele site, Cameroon): comparison between organic-poor and organic-rich waters. Chemical Geology, 140:181-206.

Walker, I. 1995. Amazonian streams and small rivers. In:Tundisi, J.G.; Bicudo, C.E.M e Matsumura Tundisi, T. (eds) Limnology in Brazil. Rio de Janeiro, Brazilian Academy of Science. p.167-193.

\section{RECEBIDO EM 06/01/2003 ACEITO EM 16/05/2005}

